\title{
The effect of alcohol consumption on household income in Ireland
}

\author{
Gillian Ormond ${ }^{\text {a, }}$, Rosemary Murphy ${ }^{\mathrm{b}}$ \\ a Department of Accounting and Economics, Waterford Institute of Technology, Ireland \\ ${ }^{\mathrm{b}}$ Department of Economics, University College Cork, Ireland
}

\section{A R T I C L E I N F O}

\section{Article history:}

Received 13 June 2016

Received in revised form

3 October 2016

Accepted 3 October 2016

JEL classification codes:

$\mathrm{C} 30$

C40

C50

I10

I18

I30

Keywords:

Alcohol

Income

Endogeneity

Selection bias

Multinomial logit

\begin{abstract}
A B S T R A C $T$
This paper presents a study of the effects of alcohol consumption on household income in Ireland using the Slán National Health and Lifestyle Survey 2007 dataset, accounting for endogeneity and selection bias. Drinkers are categorised into one of four categories based on the recommended weekly drinking levels by the Irish Health Promotion Unit; those who never drank, non-drinkers, moderate and heavy drinkers. A multinomial logit OLS Two Step Estimate is used to explain individual's choice of drinking status and to correct for selection bias which would result in the selection into a particular category of drinking being endogenous. Endogeneity which may arise through the simultaneity of drinking status and income either due to the reverse causation between the two variables, income affecting alcohol consumption or alcohol consumption affecting income, or due to unobserved heterogeneity, is addressed. This paper finds that the household income of drinkers is higher than that of non-drinkers and of those who never drank. There is very little difference between the household income of moderate and heavy drinkers, with heavy drinkers earning slightly more. Weekly household income for those who never drank is $€ 454.20$, non-drinkers is $€ 506.26$, compared with $€ 683.36$ per week for moderate drinkers and $€ 694.18$ for heavy drinkers.
\end{abstract}

(c) 2016 Published by Elsevier Inc.

\section{Introduction}

This paper investigates the effect of alcohol consumption on household income in Ireland accounting for endogeneity and selection bias using data from the 2007 Slán national health and lifestyle survey. As part of the analysis into the effect of alcohol consumption on household income, the relationship between other socioeconomic variables with both household income and alcohol status is examined. Such an analysis of the effect of alcohol consumption on income in Ireland has not been done previously, despite Ireland being among the highest consumers of alcohol in the OECD countries, with a consumption of $11.6 \mathrm{~L}$ per adult in 2012. Despite alcohol consumption in Ireland declining over the past decade, it still remains well above the OECD average (9.0 L) (OECD, 2014).

According to an OECD report Ireland has the 10th highest

\footnotetext{
* Corresponding author.

E-mail addresses: gormond@wit.ie (G. Ormond), rmurphy@ucc.ie (R. Murphy).
}

consumption levels of alcohol per capita of 40 countries (Department of Health, 2012). Alcohol consumption can place a huge cost on society. In 2007 the estimated cost of alcohol related problems in Ireland was approximately $€ 3.7 \mathrm{bn}$. On the other hand, alcohol consumption is very important to the Irish economy; in 2008 the alcohol industry in Ireland provided an estimated 50,000 whole time equivalent jobs (Department of Health, 2012). The alcohol manufacturing industry had a turnover of $€ 2.95 \mathrm{bn}$ in 2008 (Foley, 2010) and in 2009 produced $€ 1$ bn in exports and a net trade surplus of $€ 330 \mathrm{~m}$. In 2008, alcohol manufacturing and retail provided $€ 2 \mathrm{bn}$ in VAT and excise revenues to the State (Department of Health, 2012).

Ireland experienced high economic growth during the period 1994 to 2008, however in 2008 the financial crisis resulted in the Irish economy going into a recession. While the data from the Slán survey used in this study was taken in 2007 during the boom period, Butler and Hope (2015) in a study into the influence of the financial crisis on alcohol consumption in Ireland, find that despite disposable income dropping during the crises, alcohol consumption was not greatly affected. They cite two studies regarding 
hazardous drinking in Ireland; one before the recession in 2009 and the other in 2014, and both studies reported similar levels in terms of hazardous drinkers. Butler and Hope (2015) state that alcohol consumption was in fact far more responsive to different tax changes implemented by government in various budgets particularly during the period 2009 to 2013. They state that in the years that saw tax on alcohol increase, a reduction in alcohol consumption was evident and the years where there was a reduction in taxes saw an increase in alcohol consumption.

Over recent years there has been numerous policies developed and actions carried out which have helped control the levels of alcohol consumption in Ireland (Department of Health, 2012). The Alcohol Beverage Federation of Ireland (ABFI), an umbrella organisation for the drinks industry manufacturers and suppliers in Ireland, argue that previous approaches to targeting problematic drinking in Ireland has primarily been a population based approach which has reached its peak (ABFI, 2012). They suggest that going forward a target based approach, which the WHO (2007) describe as an approach targeted at vulnerable populations as opposed to the population at large, should be used.

Much research has been carried out into the effect of alcohol consumption on income (Barrett, 2002; French \& Zarkin, 1995; Hamilton \& Hamilton, 1997; Heien, 1996), however many of the earlier studies are limited in so far as drinking status is treated exogenously (French \& Zarkin, 1995; Heien, 1996); therefore, the estimated impact of alcohol consumption on earnings may reflect the reverse effect of earnings on alcohol consumption (Barrett, 2002). More recent research in this area has accounted for potential endogeneity and selection bias but this has just been done for three categories of drinkers; non-drinkers, moderate and heavy drinkers (Barrett, 2002; Hamilton \& Hamilton, 1997). Generally, findings have been that there is a positive association between moderate alcohol consumption and earnings, compared with no alcohol consumption and earnings or heavy consumption of alcohol and earnings and that this can be depicted by an inverse U-Shaped relationship between alcohol consumption and earnings (Barrett, 2002; Hamilton \& Hamilton, 1997).

Endogeneity is where an independent variable included in the model is potentially a choice variable and is determined within the context of the model (Chenhall \& Moers, 2007). In relation to the study of alcohol on income, alcohol consumption is governed in part by unobserved factors which may also be important determinants of the dependent variable income, implying the possibility that the drinking status variables may be correlated with the error term of the conditional demand equation (Barrett, 2002; Di Pietro \& Pedace, 2008; Hamilton \& Hamilton, 1997; Zarkin, French, Mroz, \& Bray, 1998). Sample selection bias arises when a sector selection is non-random due to individuals choosing a particular sector because of their personal characteristics (Heckman, 1979; Zhang, 2004). In relation to categorising individuals based on their levels of alcohol consumption, selection bias can arise as people may select into a particular drinker group due to the fact that they know that by doing so it will not have a negative effect on their income or health (Barrett, 2002; Di Pietro \& Pedace, 2008; Hamilton \& Hamilton, 1997).

The remainder of this paper is presented as follows. Section II presents the theory in relation to the issue of endogeneity bias and selection bias that can arise in the estimation of the effect of alcohol consumption on income. Section III outlines the empirical model used to analyse the effect of drinking status on income while accounting for possible selection bias and endogeneity. Section IV identifies and describes the data and empirical results. Section $\mathrm{V}$ concludes the paper.

\section{Endogeneity and selection bias of alcohol consumption and income}

French, Maclean, Sindelar, and Fang (2011) state that one of the most prominent statistical challenges in the estimation of the effect of alcohol use on labour market outcomes is the potential endogeneity of alcohol use in employment equations. Endogeneity of alcohol use may occur due to reverse causality, unobservable variables or measurement error (French et al., 2011; French \& Popovici, 2011; Leigh \& Schembri, 2004). A common way to deal with the problem of endogeneity is through the Instrumental Variables (IV) approach, whereby an instrument is used as a proxy for the endogenous explanatory variable $X$, that is highly correlated with $X$ but is uncorrelated with the error term of the demand equation (Gujarati, 1995). A difficulty however with this method is finding suitable instruments (MacDonald \& Shields, 2001; Milbourne, Otto, \& Voss, 2003). Many studies that look at the effects of lifestyle variables use panel data whereby original data is used which is then supplemented by follow-up panel data as advantage can be taken from the exogenous variables from the follow up data (Contoyannis \& Jones, 2004; French \& Popovici, 2011).

Selection Bias, arising due to individuals selecting themselves into a particular category where they have a preference, results in the sample being non-random, implying unobserved factors being correlated with both the sector choices and the primary equation which suggests a potential bias in the ordinary least squares (OLS) estimator (Devanto, 2014; Griffith \& McFall 2013; Hamilton \& Hamilton, 1997). Where this occurs choices have to be treated endogenously to get consistent estimates of the income equation coefficients (Barrett, 2002; French et al., 2011; Hamilton \& Hamilton, 1997; Zarkin et al., 1998; Zhang, 2004). Lee (1982) extends the Heckman two step model to a Multinomial Logit OLS Two Step Estimate, to allow for selection correction of polychotomous choices. Step one uses a multinomial logit model to estimate the selection equation and step two uses an OLS regression which includes the inverse mills ratio as an additional regressor, which represents the variable(s) omitted by controlling for the probability that a given observation would be observed (Griffith \& McFall 2013). By including the Inverse mills ratio in the income equations, endogeneity arising from individuals choosing their drinking status is corrected for (Barrett, 2002; Griffith \& McFall 2013; Hamilton \& Hamilton, 1997).

\section{Empirical model}

The relationship between alcohol use and household income is examined for four categories of drinkers, those who never drank, non-drinkers who are those respondents who did not have a drink in the last month or longer but cannot say that they never drank, moderate and heavy drinkers. This is carried out using the Lee Multinomial Logit OLS Two Step Estimate (Lee, 1982). Similar to the estimation of alcohol consumption on earnings by Hamilton and Hamilton (1997) and Barrett (2002), step one involves the estimation of the drinking status equation using a multinomial logit model. This estimate generates predicted values for the inverse mills ratio which are then included as an additional variable in the income equations estimated in step two. By estimating the income regression using this two-step procedure selection bias and the potential endogeneity of alcohol consumption is accounted for (Barrett, 2002; Hamilton \& Hamilton, 1997). The estimation of income regressions for each category of drinker using this two step procedure, allows household income returns to individual characteristics to differ by drinking status. This 
method results in the household income equation being estimated separately for each category of drinker, hence the issue of alcohol being an endogenous explanatory variable within the equation does not arise and instrumental variables are not required at this stage. There are many human capital and socioeconomic variables that affect income and these need to be included as independent variables in the income regression (Barrett, 2002; Hamilton \& Hamilton, 1997). All the variables included in the income equation are included in the drinking status equation to control for the effect of income on drinking (Barrett, 2002; Hamilton \& Hamilton, 1997). It is important that the independent variables in the alcohol status equation contain a variable that is not an independent variable in the income equation, otherwise the identification of the coefficient $\beta_{j}$ would be weak (Chiburis \& Lokshin, 2007). In this study there are two additional variables unique to the drinking decision that are included in the drinking status model. These are variables describing whether or not one regularly partakes in Church activities and whether or not a person who is not currently a smoker but was previously, five or more years ago.

Religion can influence how people view alcohol and the levels they consume, with findings being that Catholics seem to behave differently to other religions (Auld, 2005; Hamilton \& Hamilton, 1997). Bettendorf and Dijkgraaf (2011) estimate the effect of religion on income in the Netherlands using two measures of religion, one being church membership and the other being attendance. They use observations from 27,908 households and estimate the simultaneous effect finding that both measures are insignificant in terms of income. They conclude that religion does not affect income when properly estimated. Mangeloja (2005) carried out a study of 8 OECD countries into the effect of Religious beliefs and activity on the properties of society's cultural and ethical base, and therefore on long term economic growth. Mangeloja (2005) finds that religious beliefs have more relevance than religious attendance. This highlights that while religious attendance can affect alcohol consumption, it does not affect income.

Studies show that a correlation between whether an individual smoked at the age of 18 years and their current alcohol consumption exists (Barrett, 2002; Moore et al., 2005). This measure is viewed as a retrospective measure of an individual's attitude towards risk, the rationale being that smoking is a health risk behaviour and in part reflects an individual's attitude toward risk (Hersch \& Viscusi, 1990). Barrett (2002) looks at smoking in the past as opposed to current smoking because the retrospective measure of smoking is not likely to influence current income however current smoking behaviour is likely to affect current income. Chang, Loh, Tsai, Chiou, and Chen (2014) in looking at the relationship between smoking cessation and disease mortality risks among elderly Taiwanese, find that former smokers who quit for over 5 years were similar to those who never smoked in terms of all-cause death, lung cancer, all cause cancers, respiratory diseases and cardio vascular diseases as opposed to those who quit less than five years ago who had higher mortality rates.

As part of the analysis into the effect of alcohol consumption on income, the relationship between these other socioeconomic variables with both household income and alcohol status is examined.

(a) Estimation of the effect of Alcohol on Income using Lee Two Step Estimation

The Multinomial Logit OLS Two Step Estimate as proposed by Lee $(1982,1983)$ accounts for potential selection bias. The first step is to estimate the drinking status equation using multinomial logit model, in order to derive estimates of the vector of unknown utility parameters $\left(\gamma_{j}\right)$ by drinker type. The multinomial logit results will be used to construct the inverse mills ratio to account for individuals selecting into each sector (Greene, 2002). Individuals are assumed to select the earnings-drinking status combination that maximises their expected utility (Barrett, 2002). It is not observed directly but an indicator for each individual's choice of drinking status $\left(I_{i}\right)$ is observed. Following the formulation of Lee $(1982,1983)$, a standard multinomial logit model setting out the probability that an individual is likely to be in a particular drinking category is estimated, similar to what Hamilton and Hamilton (1997) and Barrett (2002) did in their studies.

Assume the potential income for individual $i$ with drinking status $j$ is given by equation (1). Household income for each individual are hypothesised to depend upon a vector $X_{i}$ of human capital variables and socio-demographic characteristics and $Y_{i j}$ is observed only if drinking status $j$ is chosen.

$\ln Y_{i j}=X_{i} \beta_{j}+u_{i j}$

where.

$\ln Y_{i j} \quad \log$ of household income

$\mathrm{X}$ vector of human capital variables \& socio-demographic characteristics

$\beta \quad$ coefficients on the observable characteristics

$u_{i j} \quad$ error term

$i \quad$ indexes individuals where $i=1,2, \ldots N$

$j \quad$ indexes drinking status where $j=1,2,3,4$

This specification allows income to individual characteristics to differ by drinking status. By comparing the estimated $\beta^{\prime}$ S across drinker type it is possible to gauge whether the income, given ones socio-demographic characteristics is greatest for one category of drinker over another (Barrett, 2002).

Individuals are assumed to select the income-drinking status combination that maximises their expected utility (Barrett, 2002). The $\mathrm{i}^{\text {th }}$ individuals expected utility from an income-drinking status combination is modelled by the index function (Hamilton \& Hamilton, 1997).

$U_{i j}=z_{i} \gamma_{j}+\eta_{i j}$

where.

$U_{i j} \quad$ is the expected utility of individual $i$

$z \quad$ vector containing exogenous variables affecting income or alcohol consumption

$\gamma \quad$ vector of unknown utility parameters

$\eta_{i j} \quad$ error term

$i$ indexes individuals

$j \quad$ indexes drinking status where $j=1,2,3,4$

The error terms $\eta_{i j}$ and $u_{i j}$ represent the impact of unobserved variables on utility and income. The vector $z_{i}$ contains exogenous variables hypothesised to affect either an income or preference for alcohol consumption and thus includes $X_{i}$.

Assuming that the error terms are independently and identically Gumbel distributed with the type I generalised extreme value distribution (Bali, 2003; Barrett, 2002; Hamilton \& Hamilton, 1997), a standard multinomial logit model setting out the probability that an individual is likely to be in a particular drinking category can be estimated 


$$
\operatorname{Pr}\left(I_{i}=j\right)=\frac{\exp \left(z_{i} \gamma_{i}\right)}{\sum_{s=1}^{3} \exp \left(z_{i} \gamma_{s}\right)}
$$

where.

I an indicator for each individuals choice of drinking status.

$z$ vector containing exogenous variables affecting income or alcohol consumption

$\gamma$ vector of unknown utility parameters

$i$ indexes individuals

$j \quad$ indexes drinking status

The above multinomial logit can be used to derive the correct income specifications which account for selectivity bias (Barrett, 2002; Hamilton \& Hamilton, 1997). The income equations as set out in equation (1), can then be estimated using an extension of the generalised two step procedure presented in Lee $(1982,1983)$, for each category of drinker. This provides information on the expected income if an individual were randomly allocated to a given drinking status, as well as predicted income given an individual is a particular drinker type (Barrett, 2002; Hamilton \& Hamilton, 1997). The estimation of the income equation controls for the truncated mean of the observed residual in the income equations arising from individuals selecting their preferred drinking status (Hamilton \& Hamilton, 1997). The truncated mean is a generalisation of the Heckman correction terms (Inverse Mills Ratio) to the situation where individuals choose over multiple alternatives (Hamilton \& Hamilton, 1997). By including the inverse mills ratio as an additional regressor in the income equations for each drinker type, selection bias and the possible endogeneity of alcohol status is accounted for.

\section{(b) Assumptions in the Multinomial Logit Model}

The multinomial logit makes an assumption known as the independence of irrelevant alternatives (IIA) (Hausman \& McFadden, 1984; Small \& Hsiao, 1985). The IIA property states that the ratio of the probabilities of choosing any two alternatives is independent of the attributes of any other alternative in the choice set (Hausman \& McFadden, 1984; Small \& Hsiao, 1985). In essence, this means that the relative probability of two existing outcomes is unrelated to the addition or drop of a third outcome, that is, alternative outcomes are irrelevant (Long \& Freese, 2005). In terms of drinking categories, the IIA Assumption means that if there are two drinking categories one can choose from, adding another drinking category will not affect the odds of choosing one of the initial categories (Barrett, 2002; Hamilton \& Hamilton, 1997).

A multinomial logit will need to be tested to confirm that the IIA Assumption exists. The suest-based Hausman test which is a modification of the Hausman and McFadden test, is a robust procedure implemented in Stata to deal with the issues raised by Long and Freese (Siegel \& Lucke, 2009). The Hausman test via Suest is comparable to that computed by Hausman, but uses different estimators of the variance of the different estimates (Stata, 2013); Hausman estimates $V(b-B)$ by $V(b)-V(B)$, whereas Suest estimates $\mathrm{V}(\mathrm{b}-\mathrm{B})$ by $\mathrm{V}(\mathrm{b})-\operatorname{Cov}(\mathrm{b}, \mathrm{B})-\operatorname{Cov}(\mathrm{B}, \mathrm{b})+\mathrm{V}(\mathrm{B})$. Long and Freese (2005) recommend the suest-based Hausman test for testing the IIA assumption.

\section{Data and empirical results}

(a) Data

In order to identify the impact of alcohol on the household income, this paper uses data from the 2007 Slán National Health and Lifestyle Survey, a survey commissioned by the Department of Health and Children in Ireland. In this survey a cross section of the Irish adult population, aged 18 and over, are surveyed. The selection is a random sample which is proportionately distributed across counties, locality, gender and urban/rural locations. The response rate was 10,364 people (62\%).

The dependent variables used in this study are household income and individual alcohol consumption. It is total income of the household that is reported. Individuals are presented with different income bands and are asked to select which income band is appropriate for their household in terms of the household's total net income per week. The total net take home pay includes all sources of family income including social benefits. For the purpose of econometric analysis in this paper, similar to the approach adopted by Barrett (2002), the descriptive statistics for income are derived by taking the midpoint of the household's income category and for the open upper category, a value of $10 \%$ above the lower income limit of the band is taken (Von Fintel, 2007). Previous studies into the effect of alcohol consumption on income use individual income as a measure as opposed to household income. The Slán survey does not have data available on individual income, however to control for this, the number working in the household is included as a control variable. Data relating to alcohol consumption of the household is not available and it is individual alcohol consumption levels that is reported, however Rice, Carr-Hill, Dixon, and Sutton (1998) in looking at the influence of households on drinking behaviour find that there is a high degree of commonality of consumption patterns within households, which they define as herd behaviour, and that drinking behaviour attributed to the household is $42 \%$. They conclude that this provides evidence that there is a need to view the household as a legitimate unit for policy targeting and particularly for heavy drinkers in that it may be more beneficial if policy is sympathetic to both individuals and households. Zhang, Zhang, Aleong, Baker, and Fuller-Thomson (2012) in their study into the factors that affect per capita income in Aids/HIV affected households, use household income as a measure of the dependent variable and independent variables include socio-demographic variables of those interviewed as well as household variables such as family size, number in household. Zhang et al. (2012) state that their study serves as a basis for programme and policy initiatives.

In relation to the drinking status equation, drinkers are divided into one of four categories of drinkers; those who never drank, nondrinkers, moderate and heavy drinkers. Respondents are categorised based on recommendations from the Irish Health Promotion Unit (HSE, 2008) and on their individual levels of alcohol consumption. Moderate drinkers are defined as those who had a drink in the last month or in the week prior to the survey any women who had up to 14 standard drinks and men who had up to 21 standard drinks. Non-drinkers are those who did not have a drink in the last month or longer but cannot say that they never drank. Heavy drinkers are women who drank more than 14 drinks in the week prior to the survey and men who drank more than 21 drinks.

The Slán survey includes a large number of sociodemographic characteristics, a number of which are used as explanatory variables and are shown in Table 1 . The drinking status equation contains all the variables that are in the income equation which accounts for the effect of income on alcohol consumption (Barrett, 2002; Hamilton \& Hamilton, 1997), along with other variables hypothesised to be unique to the drinking decision. 
Table 1

Descriptive statistics.

\begin{tabular}{|c|c|c|c|c|c|c|c|c|}
\hline \multirow{3}{*}{$\begin{array}{l}\text { No. observations } \\
\text { Variable }\end{array}$} & \multirow{2}{*}{\multicolumn{2}{|c|}{$\frac{\text { Never had a drink }}{1316}$}} & \multirow{2}{*}{\multicolumn{2}{|c|}{ Non drinker }} & \multirow{2}{*}{\multicolumn{2}{|c|}{ Moderate drinker }} & \multirow{2}{*}{\multicolumn{2}{|c|}{ Heavy drinker }} \\
\hline & & & & & & & & \\
\hline & Mean & Std. Dev. & Mean & Std. Dev. & Mean & Std. Dev. & Mean & Std. Dev. \\
\hline Logincome is the log of household income & 6.082 & 0.667 & 6.209 & 0.706 & 6.506 & 0.672 & 6.534 & 0.703 \\
\hline Males $=$ Individuals who are male, $0=$ female & 0.315 & 0.465 & 0.391 & 0.488 & 0.437 & 0.496 & 0.671 & 0.470 \\
\hline Age $18-29=$ those who are aged is $18-29,0=$ otherwise & 0.093 & 0.291 & 0.116 & 0.321 & 0.194 & 0.395 & 0.280 & 0.450 \\
\hline Age $30-39=$ those who are aged is $30-39,0=$ otherwise & 0.122 & 0.328 & 0.235 & 0.424 & 0.239 & 0.426 & 0.215 & 0.411 \\
\hline Age $40-49=$ those who are aged is $40-49,0=$ otherwise & 0.132 & 0.339 & 0.163 & 0.369 & 0.209 & 0.406 & 0.201 & 0.401 \\
\hline Age $50-59=$ those who are aged is $50-59,0=$ otherwise & 0.134 & 0.341 & 0.167 & 0.373 & 0.155 & 0.362 & 0.161 & 0.368 \\
\hline Age 60 to $69=$ those who are aged is $60-69,0=$ otherwise $*$ & 0.194 & 0.395 & 0.147 & 0.354 & 0.115 & 0.319 & 0.101 & 0.302 \\
\hline Age 70 plus $=$ those who are aged is 70 plus, $0=$ otherwise & 0.324 & 0.468 & 0.172 & 0.378 & 0.089 & 0.284 & 0.042 & 0.200 \\
\hline $\begin{array}{l}\text { Edprimary }=\text { Individuals who have primary school education } \\
\text { only, } 0=\text { otherwise }\end{array}$ & 0.337 & 0.473 & 0.271 & 0.445 & 0.123 & 0.328 & 0.116 & 0.320 \\
\hline $\begin{array}{l}\text { Educ. Secondary }=\text { Individuals who have completed secondary } \\
\text { education only, } 0=\text { otherwise }\end{array}$ & 0.426 & 0.495 & 0.421 & 0.494 & 0.442 & 0.497 & 0.501 & 0.500 \\
\hline $\begin{array}{l}\text { Educ. Diploma }=\text { Individuals who have a diploma or certificate, } \\
\quad 0=\text { otherwise }\end{array}$ & 0.119 & 0.323 & 0.164 & 0.370 & 0.206 & 0.404 & 0.174 & 0.379 \\
\hline $\begin{array}{l}\text { Educ. Primary Degree }=\text { Individuals who have a primary degree, } \\
\quad 0=\text { otherwise }\end{array}$ & 0.060 & 0.238 & 0.073 & 0.260 & 0.118 & 0.323 & 0.127 & 0.333 \\
\hline $\begin{array}{l}\text { Educ. Post Graduate }=\text { Individuals who have completed a } \\
\text { postgraduate/higher degree, } 0=\text { otherwise }\end{array}$ & 0.059 & 0.235 & 0.072 & 0.258 & 0.111 & 0.315 & 0.083 & 0.276 \\
\hline $\begin{array}{l}\text { Single/Never Married = Individuals who are single/never } \\
\text { married, } 0=\text { otherwise. }\end{array}$ & 0.254 & 0.435 & 0.254 & 0.435 & 0.275 & 0.447 & 0.438 & 0.497 \\
\hline $\begin{array}{l}\text { Sep/Div = Individuals who are separated or divorced, } \\
0=\text { otherwise. }\end{array}$ & 0.035 & 0.184 & 0.079 & 0.270 & 0.065 & 0.247 & 0.078 & 0.268 \\
\hline Married $=$ Individuals who are married, $0=$ otherwise. & 0.490 & 0.500 & 0.486 & 0.500 & 0.526 & 0.499 & 0.387 & 0.488 \\
\hline Widowed $=$ Individuals who are widowed, $0=$ otherwise. & 0.197 & 0.398 & 0.121 & 0.326 & 0.061 & 0.239 & 0.027 & 0.163 \\
\hline $\begin{array}{l}\text { Open country }=\text { individuals living in the open } \\
\text { country, } 0=\text { otherwise }^{*}\end{array}$ & 0.403 & 0.491 & 0.357 & 0.479 & 0.285 & 0.452 & 0.231 & 0.422 \\
\hline Village $=$ individuals living in a village, $0=$ otherwise & 0.097 & 0.295 & 0.111 & 0.314 & 0.109 & 0.311 & 0.105 & 0.307 \\
\hline Town $=$ individuals living in a town, $0=$ otherwise & 0.227 & 0.419 & 0.232 & 0.422 & 0.252 & 0.434 & 0.204 & 0.404 \\
\hline $\begin{array}{l}\text { City other than Dublin = individuals living in a city other than } \\
\text { Dublin, } 0=\text { otherwise }\end{array}$ & 0.079 & 0.270 & 0.097 & 0.296 & 0.108 & 0.310 & 0.159 & 0.366 \\
\hline $\begin{array}{l}\text { Dublin city }=\text { individuals living in Dublin city or } \\
\text { county, } 0=\text { otherwise }\end{array}$ & 0.181 & 0.385 & 0.193 & 0.394 & 0.236 & 0.425 & 0.289 & 0.454 \\
\hline $\begin{array}{l}\text { Employee }=\text { those whose current employment situation is an } \\
\text { employee at work, } 0=\text { otherwise }\end{array}$ & 0.263 & 0.440 & 0.371 & 0.483 & 0.513 & 0.500 & 0.526 & 0.500 \\
\hline $\begin{array}{l}\text { Selfemployed }=\text { those whose current employment situation is } \\
\text { self employed or in farming, } 0=\text { otherwise }\end{array}$ & 0.090 & 0.287 & 0.110 & 0.313 & 0.120 & 0.325 & 0.141 & 0.348 \\
\hline $\begin{array}{l}\text { State Training/Student }=\text { those who are students or on a state } \\
\text { training programme, } 0=\text { otherwise }\end{array}$ & 0.022 & 0.147 & 0.023 & 0.151 & 0.041 & 0.198 & 0.067 & 0.250 \\
\hline $\begin{array}{l}\text { Unemployed }=\text { those whose current employment situation is } \\
\text { unemployed, } 0=\text { otherwise }\end{array}$ & 0.033 & 0.180 & 0.026 & 0.159 & 0.026 & 0.159 & 0.063 & 0.244 \\
\hline $\begin{array}{l}\text { Homemaker }=\text { those whose current employment situation is } \\
\text { Homemaker, } 0=\text { otherwise }\end{array}$ & 0.201 & 0.401 & 0.170 & 0.376 & 0.128 & 0.334 & 0.047 & 0.212 \\
\hline $\begin{array}{l}\text { Retired }=\text { those whose current employment situation is wholly } \\
\text { retired, } 0=\text { otherwise }\end{array}$ & 0.329 & 0.470 & 0.203 & 0.402 & 0.133 & 0.340 & 0.099 & 0.300 \\
\hline $\begin{array}{l}\text { Other }=\text { those whose current employment situation is classified } \\
\text { as other, } 0=\text { otherwise }\end{array}$ & 0.014 & 0.116 & 0.007 & 0.086 & 0.009 & 0.096 & 0.005 & 0.074 \\
\hline $\begin{array}{l}\text { Num working in Household = No. of people in household } \\
\text { working } 15 \text { or more hours per week }\end{array}$ & 1.019 & 1.367 & 1.181 & 1.265 & 1.526 & 1.229 & 1.581 & 1.336 \\
\hline Race White $=$ those who are white or white Irish, $0=$ otherwise & 0.939 & 0.239 & 0.960 & 0.196 & 0.978 & 0.147 & 0.987 & 0.112 \\
\hline Race Black $=$ those who are black or white Irish, $0=$ otherwise & 0.016 & 0.125 & 0.018 & 0.132 & 0.005 & 0.069 & 0 & 0 \\
\hline Race Asian $=$ those who are Asian or Asian Irish, $0=$ otherwise & 0.025 & 0.156 & 0.009 & 0.096 & 0.004 & 0.067 & 0.002 & 0.043 \\
\hline $\begin{array}{l}\text { Race Other }=\text { those who are from another or a mixed } \\
\text { background, } 0=\text { otherwise * }\end{array}$ & 0.011 & 0.103 & 0.006 & 0.075 & 0.005 & 0.072 & 0.004 & 0.060 \\
\hline Health Poor $=$ individuals with poor health, $0=$ otherwise $*$ & 0.054 & 0.226 & 0.072 & 0.258 & 0.020 & 0.140 & 0.018 & 0.133 \\
\hline $\begin{array}{l}\text { Health excellent }=\text { individuals with excellent health, } \\
\quad 0=\text { otherwise }\end{array}$ & 0.168 & 0.374 & 0.156 & 0.363 & 0.231 & 0.421 & 0.219 & 0.414 \\
\hline $\begin{array}{l}\text { Health very good }=\text { individuals with very good health, } \\
0=\text { otherwise }\end{array}$ & 0.305 & 0.461 & 0.310 & 0.463 & 0.381 & 0.486 & 0.345 & 0.476 \\
\hline Health good $=$ individuals with good health, $0=$ otherwise & 0.302 & 0.459 & 0.294 & 0.456 & 0.282 & 0.450 & 0.320 & 0.467 \\
\hline Health Fair $=$ individuals with fair health, $0=$ otherwise & 0.167 & 0.373 & 0.166 & 0.372 & 0.084 & 0.277 & 0.098 & 0.297 \\
\hline $\begin{array}{l}\text { Church activities }=\text { individuals who regularly join in the } \\
\text { activities of Church or other religious/parish groups, } \\
\text { charitable or voluntary organisations, } 0=\text { otherwise }\end{array}$ & 0.252 & 0.434 & 0.184 & 0.388 & 0.184 & 0.387 & 0.087 & 0.282 \\
\hline $\begin{array}{l}\text { Prevsmokerfivemoreyr }=\text { Individuals who used to smoke five } \\
\quad \text { years ago or more, } 0=\text { otherwise }\end{array}$ & 0.104 & 0.306 & 0.153 & 0.360 & 0.145 & 0.352 & 0.139 & 0.347 \\
\hline
\end{tabular}

\section{(b) Results}

The multinomial logit OLS two-step estimation involves the alcohol status being estimated by a multinomial logit estimation in step one, from which the inverse mills ratio can be derived. This is then included as an additional variable in the income regression. The results are discussed below. 


\section{(1) Drinking status choice model estimates}

Results for the multinomial logit regression for drinking status are set out in Table 2. The number of observations in this regression is 7870 . Given that this is a logistic regression it is a Pseudo $R^{2}$ value that is derived and not an $R^{2}$ value. However the $P$ Value indicates that at least one of the coefficients in the model is not equal to zero. The coefficients listed indicate the effect that each variable has on the likelihood of an individual being a person who never drank, non-drinkers or heavy drinker as opposed to a moderate drinker. All the variables included in the income equation are included in the drinking status equation to control for the effect of income on drinking (Barrett, 2002). Two additional variables, unique to the drinking decision are included in the drinking status model. These are whether or not one regularly partakes in Church activities and

Table 2

Results from the Estimation of the Drinking Status Equation using the Multinomial Logit Model.

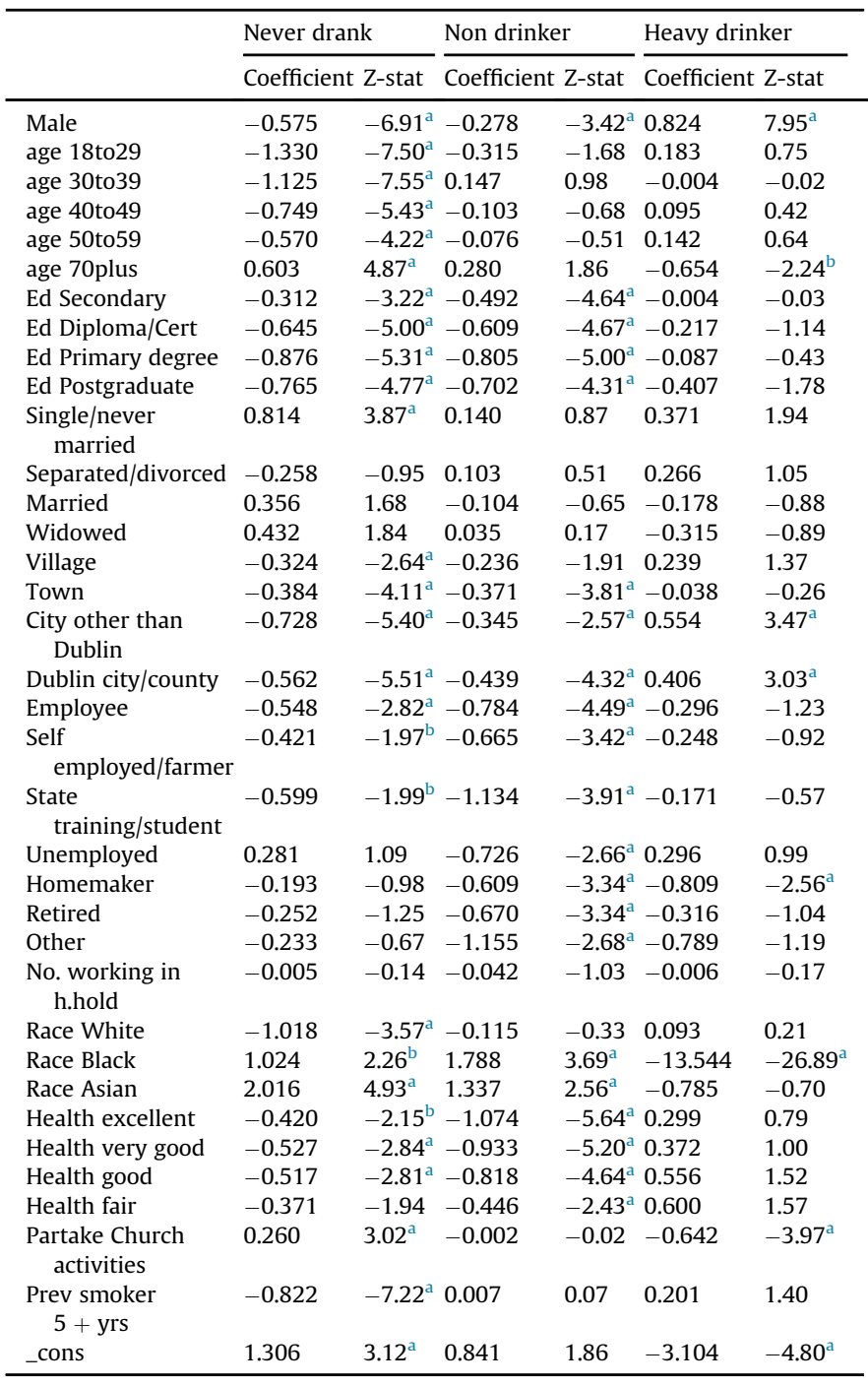

Number of obs $=7870$.

Wald chi2 $(105)=8014.72$.

Prob $>$ chi $2=0$.

Pseudo R2 $=0.0975$.

Log pseudolikelihood $=-7057.79$

Note: The average price of alcohol was included as a variable in the alcohol status equation. Price was dropped due to collinearity.

a Indicates significance at $1 \%$ level.

b Indicates significance at 5\% level. whether or not a person was previously a smoker i.e. that they smoked five or more years ago.

The gender variable is statistically significant and results show that males are less likely to never have drank or be a non-drinker and more likely to be a heavy drinker, which is similar to the findings of previous studies which find that men consume greater amounts of alcohol than women (Blow, Colleran, Oslin, Owen, \& Slaymaker, 2005; Fillmore, Golding, Leino, Ager, \& Ferrer, 1994; Moore et al., 2005; Mullahy \& Sindelar, 1996).

Previous studies show that on average people drink less as they get older, and as a result are less likely to be heavy drinkers (Auld, 2005; Barrett, 2002; Blow et al., 2005; Hamilton \& Hamilton, 1997; Moore et al., 2005; Mullahy \& Sindelar, 1996). This study has had similar findings in so far as those in the majority of categories up to age 59 years are more likely to be a moderate drinker compared with a non-drinker and never having drank, particularly those aged 18-29 years, however for those aged 70 years plus they are more likely to never have drank or be a non-drinker. For heavy drinkers age is only significant for those over 70 years, and respondents in this age category are less likely to be a heavy drinker which is similar to previous findings (Barrett, 2002; Hamilton \& Hamilton, 1997).

The results in terms of education show that all education variables are significant for the categories of non-drinkers and those who never drank. In particular, those with third level education are more likely to be a moderate drinker. Hamilton and Hamilton (1997) and Barrett (2002) find that those with a postgraduate qualification tend to be moderate drinkers as opposed to nondrinkers or heavy drinkers, and findings in this study are similar.

The variable describing those who never consumed alcohol and who are single/never married is the only significant variable describing marital status. A single person or person who never married is more likely to never have drank as opposed to a moderate drinker. Previous studies (Auld, 2005; Barrett, 2002; Hamilton \& Hamilton, 1997) find that being married is significant in terms of drinking status and that married people are less likely to be heavy drinkers and more likely to be moderate drinkers.

Where one resides has shown to be very significant in terms of ones drinking status. Those who live in a city, either in Dublin or any other city are more likely to be heavy drinkers which is similar to the findings of Su and Yen (2000). In relation to employment status, given all other predictor variables in the model being constant, respondents are more likely to be a moderate drinker as opposed to a non-drinker whatever their employment status is. In particular, students or those on state training schemes and those classified as other are least likely to be a non-drinker.

The Race variables are significant for non-drinkers and for heavy drinkers the variable describing those of black race is significant. A white person is more likely to be a moderate drinker as opposed to a never having drank and Asians and Blacks are more likely to be non-drinkers or those who never drank.

All the health status variables are significant for non-drinkers and all except the variable describing health as fair for those who never drank. In particular those with excellent, very good or good health, are more likely to be a moderate drinker which is similar to the findings of previous studies (Bau, Bau, Rosito, Manfroi, \& Fuchs, 2007; Berger et al., 1999; Klatsky, Armstrong, Friedman, \& Sidney, 2001).

The explanatory variable describing whether or not people regularly partake in Church activities is a very significant variable for those who never drank and for heavy drinkers. Results show that those involved in Church activities are more likely to never have consumed alcohol.

The variable describing those who are no longer smokers but who previously smoked 5 or more years ago, is only significant for 
those who never drank and results show these respondents are more likely to be a moderate drinker compared with a being a person who never drank. Barrett (2002) finds a correlation between an individual who previously smoked at the age of 18 years and ones alcohol consumption and argues that this is the case as it is a retrospective measure of an individual's attitude towards risk.

\section{(2) Grouped Income Regression Estimates}

Results for the household income regressions estimated by OLS and corrected for selection bias, using the Slán 2007 dataset, are presented in Table 3. Looking at all four categories of drinkers, the number of observations for moderate drinkers is by far the greatest. The regressions for all categories have relatively high $\mathrm{R}^{2}$ values which means that a relatively high percentage of the variation in income for each category of drinker can be explained by the model.

Gender is a significant variable in the household income regression for both non-drinkers and moderate drinkers. There is a positive effect on household income for male non-drinkers and moderate drinkers similar to the findings of others (Zhang, Hannum, \& Wang, 2008). The age variable appears to be much more significant for the categories those who never drank, nondrinkers and moderate drinkers showing that younger respondents in these categories are more likely to have higher incomes than those who are older, similar to the findings of Hamilton and Hamilton (1997). Barrett (2002) shows that the age profile for moderate drinkers peaks at ages 40-49years, whereas this study shows the age income peaks for non-drinkers and those who never drank, at age $30-39$ years.

Education is a very significant variable in the household income regression for all drinker types. In particular drinker types with a primary degree or a postgraduate degree have higher household incomes compared to those with a primary education only which is consistent with previous findings (Barrett, 2002; French \& Zarkin, 1995; Heien, 1996). Heavy drinkers who have a postgraduate qualification tend to have the highest household income holding the other variables constant.

Being married results in a higher household income for all categories except non-drinkers. For non-drinkers and moderate drinkers, there is a negative household income premium associated with being single/never married, separated/divorced and widowed compared with those in the base category who are cohabiting. This

Table 3

Results from the estimation of the Income Equation by OLS regression accounting for selection bias.

\begin{tabular}{|c|c|c|c|c|c|c|c|c|}
\hline & \multicolumn{2}{|c|}{ Never drank } & \multicolumn{2}{|c|}{ Non drinkers } & \multicolumn{2}{|c|}{ Moderate drinkers } & \multicolumn{2}{|c|}{ Heavy drinkers } \\
\hline & Coeff. & z-stat & Coeff. & z-stat & Coeff. & z-stat & Coeff. & z-stat \\
\hline Male & 0.039 & 0.91 & 0.139 & $2.97^{\mathrm{a}}$ & 0.071 & $4.40^{\mathrm{a}}$ & 0.082 & 1.84 \\
\hline age18to29 & 0.150 & 1.48 & 0.157 & 1.85 & 0.115 & $2.54^{\mathrm{b}}$ & 0.291 & $1.69^{\mathrm{b}}$ \\
\hline age30to39 & 0.164 & $2.36^{\mathrm{b}}$ & 0.280 & $3.70^{\mathrm{a}}$ & 0.126 & $3.32^{\mathrm{a}}$ & 0.090 & 0.67 \\
\hline age40to49 & 0.152 & $2.59^{\mathrm{b}}$ & 0.106 & 1.64 & 0.129 & $3.33^{\mathrm{a}}$ & 0.107 & 0.80 \\
\hline age50to59 & 0.027 & 0.44 & 0.085 & 1.29 & 0.117 & $3.24^{\mathrm{a}}$ & 0.047 & 0.38 \\
\hline age70plus & -0.023 & -0.42 & -0.170 & $-2.41^{\mathrm{b}}$ & -0.067 & -1.84 & -0.157 & -1.11 \\
\hline Ed Secondary & 0.048 & 1.28 & 0.161 & $2.09^{\mathrm{b}}$ & 0.189 & $5.89^{\mathrm{a}}$ & 0.289 & $3.32^{\mathrm{a}}$ \\
\hline Ed Diploma/Cert & 0.174 & $2.89^{\mathrm{a}}$ & 0.219 & $2.35^{\mathrm{b}}$ & 0.317 & $9.09^{\mathrm{a}}$ & 0.469 & $4.06^{\mathrm{a}}$ \\
\hline Ed Primary degree & 0.394 & $5.79^{\mathrm{a}}$ & 0.448 & $4.07^{\mathrm{a}}$ & 0.487 & $11.55^{\mathrm{a}}$ & 0.663 & $5.00^{\mathrm{a}}$ \\
\hline Ed Postgraduate & 0.400 & $5.16^{\mathrm{a}}$ & 0.410 & $3.46^{\mathrm{a}}$ & 0.562 & $13.85^{\mathrm{a}}$ & 0.731 & $4.95^{\mathrm{a}}$ \\
\hline Single nevermarried & -0.105 & -1.03 & -0.404 & $-8.30^{\mathrm{a}}$ & -0.168 & $-3.73^{\mathrm{a}}$ & -0.143 & -1.51 \\
\hline Separated/divorced & 0.063 & 0.45 & -0.285 & $-3.06^{\mathrm{a}}$ & -0.287 & $-6.24^{\mathrm{a}}$ & -0.065 & -0.78 \\
\hline Married & 0.271 & $2.76^{\mathrm{a}}$ & 0.014 & 0.26 & 0.168 & $4.87^{\mathrm{a}}$ & 0.322 & $5.12^{\mathrm{a}}$ \\
\hline Widowed & -0.103 & -0.94 & -0.281 & $-3.84^{\mathrm{a}}$ & -0.188 & $-4.56^{a}$ & 0.043 & 0.31 \\
\hline Village & -0.039 & -0.74 & -0.027 & -0.37 & -0.013 & -0.54 & 0.042 & 0.64 \\
\hline Town & 0.028 & 0.66 & 0.006 & 0.10 & -0.062 & $-2.83^{\mathrm{a}}$ & 0.002 & 0.03 \\
\hline City other than Dublin & 0.062 & 1.05 & -0.018 & -0.27 & -0.031 & -1.15 & 0.030 & 0.34 \\
\hline Dublin city/county & 0.136 & $2.93^{\mathrm{a}}$ & 0.086 & 1.16 & 0.123 & $5.87^{\mathrm{a}}$ & 0.091 & 1.56 \\
\hline Employee & 0.406 & $4.13^{\mathrm{a}}$ & 0.238 & 1.80 & 0.293 & $4.36^{\mathrm{a}}$ & 0.648 & $3.89^{\mathrm{a}}$ \\
\hline Selfemployed/farmer & 0.274 & $2.36^{\mathrm{b}}$ & 0.180 & 1.35 & 0.289 & $4.32^{\mathrm{a}}$ & 0.708 & $4.14^{\mathrm{a}}$ \\
\hline State training/student & 0.332 & $1.99^{\mathrm{b}}$ & -0.105 & -0.38 & -0.038 & -0.48 & 0.081 & 0.39 \\
\hline Unemployed & -0.141 & -1.07 & -0.308 & -1.48 & -0.143 & $-1.50^{\mathrm{b}}$ & 0.205 & 1.19 \\
\hline Homemaker & 0.251 & $2.57^{\mathrm{a}}$ & 0.084 & 0.86 & 0.194 & $3.10^{\mathrm{a}}$ & 0.335 & 1.40 \\
\hline Retired & 0.200 & $2.01^{\mathrm{b}}$ & 0.016 & 0.11 & 0.190 & $2.99^{\mathrm{a}}$ & 0.325 & 1.45 \\
\hline Other & 0.071 & 0.43 & 0.141 & 0.70 & -0.007 & -0.06 & 0.210 & 0.60 \\
\hline No. working in house hold & 0.090 & $2.82^{\mathrm{a}}$ & 0.124 & $3.18^{\mathrm{a}}$ & 0.134 & $6.60^{\mathrm{a}}$ & 0.128 & $3.25^{\mathrm{a}}$ \\
\hline Race White & 0.342 & $2.02^{\mathrm{b}}$ & 0.261 & 1.63 & 0.093 & 1.46 & -0.109 & -0.49 \\
\hline Race Black & -0.137 & -0.80 & -0.250 & -0.65 & -0.127 & -0.74 & (omitted) & \\
\hline Race Asian & 0.223 & 1.10 & -0.313 & -1.11 & -0.027 & -0.19 & -0.159 & -0.47 \\
\hline Health excellent & 0.218 & $2.57^{\mathrm{a}}$ & 0.024 & 0.15 & 0.102 & 1.82 & 0.232 & 1.24 \\
\hline Health very good & 0.132 & 1.72 & 0.094 & 0.72 & 0.042 & 0.77 & 0.272 & 1.51 \\
\hline Health good & 0.059 & 0.73 & 0.091 & 0.79 & 0.003 & 0.05 & 0.151 & 0.89 \\
\hline Health fair & 0.038 & 0.52 & 0.061 & 0.66 & -0.048 & -1.01 & 0.134 & 0.79 \\
\hline Mills Ratio & 0.121 & 1.09 & 0.275 & 0.80 & -0.268 & $-2.26^{\mathrm{b}}$ & 0.196 & 0.42 \\
\hline _cons & 4.899 & $21.10^{\mathrm{a}}$ & 5.039 & $15.87^{\mathrm{a}}$ & 5.682 & $34.55^{\mathrm{a}}$ & 4.984 & $8.02^{\mathrm{a}}$ \\
\hline Never drank & \multicolumn{3}{|c|}{ Non drinkers } & \multicolumn{3}{|c|}{ Moderate drinkers } & \multicolumn{2}{|c|}{ Heavy drinkers } \\
\hline Number of obs $=1150$ & \multicolumn{3}{|c|}{ Number of obs $=977$} & \multicolumn{3}{|c|}{ Number of obs $=5216$} & \multicolumn{2}{|c|}{ Number of obs $=527$} \\
\hline Replications $=50$ & \multicolumn{3}{|c|}{ Replications $=50$} & \multicolumn{3}{|c|}{ Replications $=50$} & \multicolumn{2}{|c|}{ Replications $=38$} \\
\hline Wald chi2 $2(34)=3135.48$ & \multicolumn{3}{|c|}{ Wald chi2 $2(34)=8095.44$} & \multicolumn{3}{|c|}{ Wald $\operatorname{chi} 2(34)=8882.43$} & \multicolumn{2}{|c|}{ Wald chi2 $(33)=29,602.12$} \\
\hline Prob $>$ chi $2=0.0000$ & \multicolumn{3}{|c|}{ Prob $>$ chi $2=0.0000$} & \multicolumn{3}{|c|}{ Prob $>$ chi $2=0.0000$} & \multicolumn{2}{|c|}{ Prob $>$ chi $2=0.0000$} \\
\hline R-squared $=0.4591$ & \multicolumn{3}{|c|}{ R-squared $=0.5266$} & \multicolumn{3}{|c|}{ R-squared $=0.4606$} & \multicolumn{2}{|c|}{$\mathrm{R}$-squared $=0.5416$} \\
\hline Adj R-squared $=0.4426$ & & squared & & & ared $=0$ & & Adj R-square & 5110 \\
\hline Root MSE $=0.4866$ & & MSE $=0$ & & & $=0.4902$ & & Root MSE $=$ & \\
\hline
\end{tabular}

\footnotetext{
a Indicates significance at $1 \%$ level.

b Indicates significance at 5\% level.
} 
is similar to previous findings in relation to the income of men (Ahituv \& Lerman, 2007; Berger \& Leigh, 1988; Loh, 1996; Schoeni, 1995).

In terms of where respondents live, both those who never drank and moderate drinkers living in Dublin city or county have higher incomes while income of moderate drinkers who live in towns is less, when compared to those living in the country.

For all categories of drinkers except non-drinkers, the variables describing those who are employees or self employed have a positive household income effect as do homemakers who are moderate drinkers or never drank when compared with those with a disability. Retired respondents who never drank and moderate drinkers enjoy a positive household income effect.

The number of people in the household who are working is significant across all drinker types and has a positive correlation with household income. Berger and Leigh (1988) show in their study that race differences in terms of wages are insignificant, and findings using the Slán 2007 dataset are similar in so far as, only the race variable describing white people is significant for those who never drank. White people who never drank alcohol tend to have higher incomes.

The health variable describing those in excellent health is only significant in the income regression of those who never drank, indicating a higher household income premium for these respondents compared to those with poor health, which is in line

\section{(3) Income differentials by drinker type}

After estimating the model, appropriately accounting for selection bias of alcohol consumption, household income is predicted for each category of drinking similar to what was done by Chiburis and Lokshin (2007). Previous studies show a positive association between income and moderate alcohol consumption, compared with income of either non or heavy consumers of alcohol (Barrett, 2002; French \& Zarkin, 1995; Hamilton \& Hamilton, 1997). Other studies find that while there was a positive correlation between income and alcohol consumption, the drop in income associated with heavy consumption of alcohol compared with moderate consumption, is not found (Bastida, 2006; Zarkin et al., 1998). Overall findings in this study show that drinkers have a higher household income than non-drinkers when controlling for differences in age, human capital and other socio-demographic characteristics and controlling for the endogenous relationship between alcohol consumption and income. There is very little difference between the household income of moderate and heavy drinkers, however it should be noted that the numbers of respondents classified as moderate drinkers is 5626 compared with 553 heavy drinkers. Income of non-drinkers is substantially less. Weekly household income for those who never drank is $€ 454.20$, nondrinkers is $€ 506.26$, compared with $€ 683.36$ per week for moderate drinkers and $€ 694.18$ for heavy drinkers (Fig. 1).

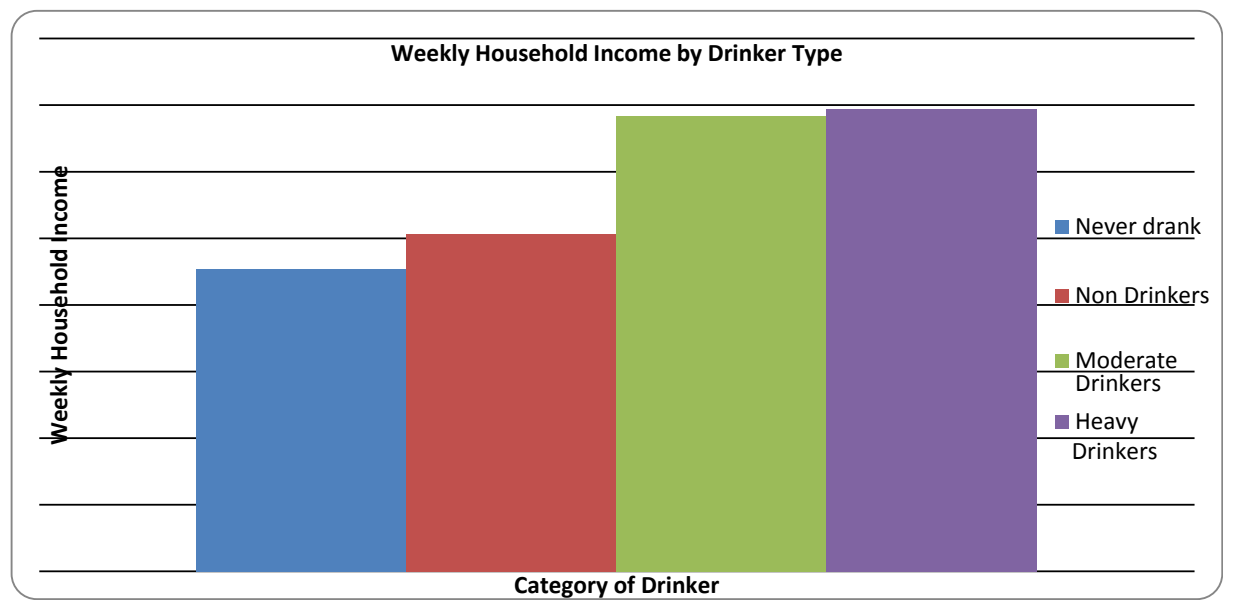

Fig. 1. Household total net income per week $(€)$ for all Categories of drinkers.

with Grossman (1972) argument whereby if one can improve their health status they are then in a position to work more and this then results in ones income increasing.

The Inverse Mills Ratio is significant for moderate drinkers only, indicating that there is a selection effect into moderate drinking. The selection effect is negative indicating that individuals with certain unobserved characteristics have allocated themselves into the moderate drinking category specifically because of having certain characteristics and these individuals are likely to earn less than a random set of comparable individuals who are moderate drinkers (Devanto, 2014; Hamilton \& Hamilton, 1997). Hamilton and Hamilton (1997) and Barrett (2002) find that the Mills Ratio for non and moderate drinkers is insignificant however in contrast to this study the Inverse Mills Ratio for heavy drinkers is significant indicating that individuals who self select into heavy drinking earn more on average than an individual with identical observable characteristics drawn at random from the workforce would earn as a heavy drinker.
Average weekly household income for those who never drank and non-drinkers is substantially less than that of moderate and heavy drinkers. There is very little difference between the income of moderate and heavy drinkers.

Household income is analysed further using the Oaxaca technique, an often used methodology to study labour market outcomes by groups. This Blinder-Oaxaca decomposition is a standard technique used to divide the wage differential between two groups into a part that is explained by differences in observable characteristics and a residual that cannot be explained by differences in characteristics (Jann, 2008; Pearlman \& Tsao, 2009). This technique provides further insight into the differences in income and allows the identification of whether the differences are due to characteristics or are unexplained (Hamilton \& Hamilton, 1997).

The explained part represents the part of the wage gap that is attributable to differences in group characteristics, that is the differences in wages that exists between groups if all groups had the 
Table 4

Decomposition of Income Differentials between the different categories of drinkers.

\begin{tabular}{|c|c|c|c|c|c|c|}
\hline & \multicolumn{6}{|c|}{ Differentials in income } \\
\hline & $\begin{array}{l}\text { Non drinker less } \\
\text { individual } \\
\text { who never drank }\end{array}$ & $\begin{array}{l}\text { Moderate drinker less } \\
\text { individual } \\
\text { who never drank }\end{array}$ & $\begin{array}{l}\text { Heavy drinker less } \\
\text { individual } \\
\text { who never drank }\end{array}$ & $\begin{array}{l}\text { Moderate drinker } \\
\text { less non drinker }\end{array}$ & $\begin{array}{l}\text { Heavy drinker } \\
\text { less non drinker }\end{array}$ & $\begin{array}{l}\text { Heavy drinker less } \\
\text { moderate drinker }\end{array}$ \\
\hline Differential & \multicolumn{6}{|l|}{ Coefficient } \\
\hline Prediction 1 & 6.227 & 6.527 & 6.542 & 6.527 & 6.542 & 6.524 \\
\hline Prediction 2 & 6.118 & 6.118 & 6.118 & 6.227 & 6.118 & 6.527 \\
\hline \multirow[t]{2}{*}{ Difference } & 0.108 & 0.408 & 0.424 & 0.299 & 0.424 & 0.0157 \\
\hline & \multicolumn{6}{|l|}{ Decomposition } \\
\hline Explained & 0.134 & 0.323 & 0.291 & 0.225 & 0.290 & -0.0425 \\
\hline Unexplained & -0.025 & 0.085 & 0.133 & 0.075 & 0.133 & 0.0582 \\
\hline
\end{tabular}

same characteristics (Jann, 2008). The unexplained part is often used as a measure for discrimination, but it also subsumes the effects of group differences in unobserved predictors (Jann, 2008). The household income decompositions are reported in Table 4.

The household income differentials between each of the categories of drinkers are statistically significant except in terms of the difference between moderate and heavy drinkers. The income decompositions reveal a large income premium for moderate and heavy drinkers relative to those who never drank and relative to non-drinkers.

Income differentials show that comparing the income of moderate drinkers to those who never drank, 79 percent can be explained by differences in endowments and comparing income of moderate drinkers to non-drinkers 75 percent can be explained by endowments. This highlights that between 21 percent and 25 percent of the higher income enjoyed by this group of moderate drinkers is unexplained. Hamilton and Hamilton (1997) refer to the unexplained component as being the pure income differential and isolates the effect of alcohol consumption on income.

In terms of the differences in income between heavy drinkers compared to both non-drinkers and those who never drank, 68-69 percent can be attributed to endowments and 31-32 percent is unexplained. The difference in income between non-drinkers and those who never drank is found to be attributed to differences in endowments.

Overall the decomposition of income differentials shows that a substantial part of the difference in income between drinkers and individuals who don't drink or who never have is unexplained and is not due to endowments.

\section{(4) Post estimation diagnostics}

\section{Testing the specification of the model}

Both the Hausman test and the Suest-based Hausman are used to test of the Independence of Irrelevant Alternatives (IIA). The null hypothesis that the IIA is valid is tested and both tests show that the null cannot be rejected hence the multinomial logit model can be applied.

The significance of each of the variables in both the alcohol status estimation and the income equation is assessed using the $\mathrm{z}$ statistics. The Likelihood Ratio test is used to evaluate the relevance of each variable in the model and ensure that each variable is beneficial to the model. The Wald Test and the F Test show that the models are statistically significant. Bootstrap estimations have been used in the estimation of the income regression in step two.

\section{Endogeneity bias}

Selection bias treats the sector selection, in this case alcohol consumption, endogenously. Selection bias of alcohol consumption is accounted for; hence the endogeneity of alcohol consumption is accounted for. Separate income regressions are then estimated by drinker type which include the Inverse Mills ratio as an additional regressor, which similar to the approach adopted in previous studies (Barrett, 2002; Hamilton \& Hamilton, 1997). Barrett (2002) tests for the possible endogeneity of marital status to the drinking decision but finds that endogeneity does not exist. In this study suitable proxy instruments are not available for marital status and health status variables, however when the drinking status choice equation and the income equations are analysed excluding marital status, the results reported are not sensitive to the treatment of marital status. Similarly, where both income and alcohol consumption regressions are run omitting the health status variables, the results are not sensitive to this.

A cross tab analysis was carried out between income and the two variables deemed to be relevant in terms of alcohol consumption only; Partake in Church activities and Previous Smoker five or more years ago. In both cases the correlation between the two variables was found to be extremely weak. In addition to this the income regression including these two additional variables, was estimated for each category of drinker and in all instances they were found to be insignificant in the income equation.

\section{Conclusion}

This paper presents an empirical study of the effect of individual alcohol consumption on household income in Ireland while accounting for endogeneity and selection bias. The relationship between household income and alcohol status with different socioeconomic variables is examined.

The drinking status equation is estimated using data from the 2007 Slán survey, using the Lee Multinomial Logit Ordinary Least Squares (OLS) Two Step Estimate. By estimating the income regression using this two step procedure potential endogeneity and selection bias of alcohol consumption are accounted for. This estimation allows the relationship between household income and the different categories of alcohol status with different personal and socioeconomic variables to be examined.

The major finding from this analysis is that in Ireland, drinking does affect household income, whereby household income of drinkers is higher than non-drinkers and those who never drank, while controlling for the endogenous relationship between alcohol consumption and income and controlling for differences in human capital and other socio-demographic characteristics. Findings showing that moderate drinkers are better off in terms of household income is similar to that of previous studies, but income of heavy drinkers is higher which is in contrast to most previous findings (Barrett, 2002; Hamilton \& Hamilton, 1997; Lye \& 
Hirschberg, 2004; Zarkin et al., 1998). The difference between the income of moderate and heavy drinkers is however very small. Income of non-drinkers and those who never drank is substantially less than both categories of drinkers.

Implications of these findings are that there are benefits in terms of household income from the consumption of alcohol and this should be taken into account in the development of policy. While adopting a population based approach to policy around reducing alcohol consumption may benefit the majority of individuals, some individuals, namely moderate consumers of alcohol, could reduce their alcohol consumption to levels resulting in their household income falling.

Despite such evidence, the majority of recent recommendations around alcohol policy in Ireland set out by the Steering Group on National Substance Misuse Strategy in February 2012 (Department of Health, 2012), are population based and no reference is made to the potential benefits of moderate levels of alcohol consumption and the fact that some individuals may be adversely affected by these measures, with the majority of recommendations being around the supply side of alcohol. Many of these proposals have been introduced in the Public Health (Alcohol) Bill in 2015 which is due to go before the Houses of the Oireachtas in 2016, for debate and approval. This Bill is part of a suite of measures designed to reduce alcohol consumption. Some of the proposals contained in this Bill include provisions to prevent the sale of cheap alcohol, health labelling and warnings on products, separation of alcohol within stores and restrictions on advertising and marketing. Ludbrook, Petrie, McKenzie, and Farrar1 (2012) acknowledge that concerns have been expressed that measures such as tax increases or minimum pricing, will unfairly penalise moderate drinkers of modest means and hence such policies could be regressive. They state that population level approaches may be more cost effective in countries with higher per capita consumption levels and hence are often implemented despite the optimal strategy being to probably combine both approaches (Ludbrook et al., 2012). Wagenaar, Salois, Komro (2009) find that price elasticity of demand for heavy drinkers is -0.28 indicating that while price/tax increases causes a reduction in heavy drinking, the magnitude of the effect is small. The results of this study using Irish data from over 10,000 people shows the majority of respondents are classified as moderate drinkers and similar to findings in other countries, moderate consumers of alcohol in Ireland enjoy higher household income than non-drinkers. By adopting a population based approach to policy such as that proposed in Ireland, many individuals in this group could be worse off as a result of such policies being implemented. Adams and White (2005) state that such an approach to policy brings about an ethical issue in that while it may benefit the majority of individuals there may be a small number of individuals, namely moderate consumers of alcohol, who will be at harm or disadvantaged from such an approach. It is recommended that the approach to policy around the misuse of alcohol consumption is looked at again in the context of the tailoring of policies to particular groups of individuals rather than providing a one size fits all approach and perhaps as suggested by Rice et al. (1998) there is a need to consider the household as well as individuals in terms of policy targeting, particularly in terms of heavy drinkers. The at risk individuals should be targeted which would ensure that when people drink they do so in as safe a manner as possible and selective enforcement of policies around the misuse of alcohol should be looked at to ensure that all individuals are protected from harm.

When one looks at the statistics around the levels of alcohol consumption in Ireland (OECD, 2014), it is evident that there is a drinking culture present and it could be the case that such a drinking culture has an impact on income in Ireland. MacDonald and Shields (2001) suggest that the positive effect of moderate alcohol use on income may be related to social networking. They argue that consuming alcohol often coincides with socialising and hence spending more time with work colleagues and management. Such social networking can allow management to see their staff in a different light and to be provided with valuable information about their staff and what motivates them. This in turn can help individual's careers and thus stimulate their wages. The Slán dataset does not provide data that can measure such a social impact of alcohol consumption on income.

Harris, Ramful, and Shao (2006) argue that alcohol consumption could be viewed as being ordered data and should be estimated as so. This is something that previous studies into the effect of alcohol consumption on income have not accounted for (Barrett, 2002; Hamilton \& Hamilton, 1997). To account for the ordered nature of alcohol consumption, estimation could be carried out by ordered probit as opposed to multinomial logit.

\section{References}

Adams, J., \& White, M. (2005). When the population approach to prevention puts the health of individuals at risk. International Journal of Epidemiology, 34(1) $40-43$.

Ahituv, A., \& Lerman, R. (2007). How do marital status, work Effort and wage rate Interact? Demography, 44(3), 623-647.

Alcohol Beverage Federation of Ireland. (2012). The national substance misuse strategy Minority report by the alcohol Beverage Federation of Ireland. Dublin: ABFI, 2012.

Auld, C. (2005). Smoking, drinking and income. Journal of Human Resources, 2 505-518.

Bali, T. (2003). The generalised extreme value distribution. Economics Letters, 79(3), 423-427.

Barrett, G. (2002). The effect of alcohol consumption on earnings. Economic Record 78(1), 79-96

Bastida, E., \& Soydemir, G. (2006). Alcohol use and Earnings, Findings from a community based study. Eastern Economic Journal, 32(4), 617-628.

Bau, P., Bau, C., Rosito, G., Manfroi, W., \& Fuchs, F. (2007). Alcohol consumption, Cardiovascular health and Endothelial function markets. Alcohol, 41(7).

Berger, K., Ajani, U., Kase, C., Gaziano, J., Buring, J., Glynn, R., et al. (1999). Light to moderate alcohol consumption and the risk of stroke among US male physicians. The New England Journal of Medicine, 341, 1557-1564.

Berger, M., \& Leigh, J. (1988). The Effect of alcohol use on wages. Journal of Applied Economics, 20, 1343-1351.

Bettendorf, L., \& Dijkgraaf, E. (2011). The bicausal relation between religion and income. Applied Economics, 43, 1351-1363.

Blow, P., Colleran, C., Oslin, D., Owen, F., \& Slaymaker, V. (2005). Treatment outcomes for alcohol dependence among middle-aged and older adults. Addictive Behaviors, 30(7), 1431-1436.

Butler, S., \& Hope, A. (2015). Ireland's financial crisis and its influence on alcohol and drug issues. Nordic Studies on Alcohol and Drugs, 32, 2015.

Chang, L., Loh, E., Tsai, Y., Chiou, S., \& Chen, L. (2014). Clinical benefits of smoking cessation in reducing all-cause and disease-specific mortality among olde people in Taiwan: A 10-year nationwide retrospective cohort study. European Geriatric Medicine, 5(2014), 149-154.

Chenhall, R., \& Moers, F. (2007). The issue of endogeneity within theory-based, Quantitative management accounting research. European Accounting Review, 16(1), 173-195.

Chiburis, R., \& Lokshin, M. (2007). Maximum Likelihood and two-step estimation of an ordered probit selection model. The Stata Journal, 7(2), 167-182.

Contoyannis, P., \& Jones, A. M. (2004). Socio-economic status, health and lifestyle. Journal of Health Economics, 23, 965-995.

Department of Health, Ireland. (2012). Steering group report on a national substance misuse strategy. February 2012.

Devanto, S. P. (2014). Does minimum wage affect hours worked of paid employment in Indonesia? International Journal of Social Economics, 41(5), 362-379.

Di Pietro, G., \& Pedace, L. (2008). Changes in the returns to education in Argentina. Journal of Applied Economics, XI(2), 259-279.

Fillmore, K., Golding, J., Leino, V., Ager, C., \& Ferrer, H. (1994). Societal-level predictors of groups' drinking patterns: A research Synthesis from the Collaborative alcohol-relation Longitudinal Project. American Journal of Public Health, 84(2), 247-253.

Foley, A. (2010). The economic contribution of the drinks industry. Dublin: Drinks Industry Group of Ireland.

French, M., Maclean, J., Sindelar, J., \& Fang, H. (2011). The morning after: Alcohol misuse and employment problems. Applied Economics, 43, 2705-2720.

French, M. T., \& Popovici, I. (2011). That instrument is Lousy! In Search of Agreement when using instrumental variables estimation in substance Use research. Health Economics, 20(2), 127-146.

French, M., \& Zarkin, G. (1995). Is moderate alcohol use related to wages? Evidence from four worksites. Journal of Health Economics, 14, 319-344. 
Greene, W. (2002). Econometric analysis (5 ${ }^{\text {th }}$ ed.). Upper Saddle River, New Jersey: Practice Hall.

Griffith, A., \& McFall, T. (2013). Using PGA Tour results to Illustrate the effects of selection bias. The Journal of Economic Education, 44(3), 238-248.

Grossman, M. (1972). On the concept of health capital and the demand for health. Journal of Political Economy, 80(2), 223-255. Mar/Apr72.

Gujarati, D. (1995). Basic econometrics (3rd ed.). McGraw-Hill.

Hamilton, V., \& Hamilton, B. (1997). Alcohol and Earnings; does drinking yield a wage premium? Canadian Journal of Economics, 30(1), 135-151.

Harris, M., Ramful, P., \& Shao, Z. (2006). An ordered generalised extreme value model with application to alcohol consumption in Australia. Journal of Health Economics, 25, 782-801.

Hausman, J., \& McFadden, D. (1984). Specification tests for the multinomial logit model. Econometrica, 52(5), 1219-1240.

Health Service Executive (2008). (URL:http://www.hse.ie/eng/services/news Image_Bank/Alcohol_Awareness_Posters.pdf) (Accessed: 2008).

Heckman, J. (1979). .Sample selection bias as a specification error. Econometrica, 47(1), 153-161.

Heien, D. (1996). Do drinkers earn less? Southern Economic Journal, 63, 60-68.

Hersch, J.. \& Viscusi, W. (1990). Cigarette smoking, seatbelt use and differences in wage-risk tradeoffs. Journal of Human Resources, 25(2), 202-227.

Jann, B. (2008). The Blinder-Oaxaca decomposition for linear regression models. The Stata Journal, 8(4), 453-479.

Klatsky, A., Armstrong, M., Friedman, G., \& Sidney, S. (2001). Alcohol drinking and risk of hospitalisation for ischemic stroke. American Journal of Cardiology, 88, 703-706.

Lee, L. (1982). Some approaches to the correction of selectivity bias. The Review of Economic Studies, 49, 355-372.

Lee, L.-F. (1983). Generalised econometric models with selectivity. Econometrica 51(2), 507-512.

Leigh, P., \& Schembri, M. (2004). Instrumental variables technique: Cigarette price provided better estimate of effects of smoking on SF-12. Journal of Clinical Epidemiology, 57, 284-293.

Loh, E. (1996). Productivity Differences and the marriage premium for white males. Journal of Human Resources, 31, 566-589.

Long, J., \& Freese, J. (2005). Regression models for Categorical dependent variables using Stata $\left(2^{\text {nd }}\right.$ ed.). College Station, TX: Stata Press.

Ludbrook, A., Petrie, D., McKenzie, L., \& Farrar1, S. (2012). Tackling alcohol misuse Purchasing patterns affected by minimum pricing for alcohol. Applied Health Economic Health Policy, 10(1), 51-63, 2012.

Lye, J., \& Hirschberg, J. (2004). Alcohol consumption, smoking and wages. Applied Economics, 36, 1807-1817.

MacDonald, Z., \& Shields, M. (2001). The impact of alcohol consumption on Occupational Attainment in England. Economica, 68(271), 427-453, 2001.

Mangeloja, E. (2005). Economic growth and religious production efficiency. Applied Economics, 37, 2349-2359.

Milbourne, R., Otto, G., \& Voss, G. (2003). Public Investment and economic growth. Applied Economics, 35, 527-540.
Moore, A., Gould, R., Reuben, D., Greendale, G., Carter, K., Zhou, K., et al. (2005). Longitudinal patterns and predictors of alcohol consumption in the United States. American Journal of Public Health, 95(3), 458-465.

Morgan, K., McGee, H., Watson, D., Perry, I., Barry, M., Shelley, E., et al. (2008). SLÁN 2007: Survey of lifestyle, attitudes \& nutrition in Ireland. Main report. Dublin: Department of Health and Children.

Mullahy, J., \& Sindelar, J. (1996). Employment, unemployment and problem drinking. Journal of Health Economics, 1996, 409-434.

OECD. (2014). Oecd health statistics 2014 how does Ireland compare? [Online] http:/ www.oecd.org/els/health-systems/Briefing-Note-IRELAND-2014.pdf (Accessed April 2015)

Pearlman, A., \& Tsao, T. (2009). Decomposition of the black-white wage differential in the Physician market (Economics Working Paper). Levy Economics Institute.

Rice, N., Carr-Hill, R., Dixon, P., \& Sutton, M. (1998). The influence of households on drinking behaviour: A Multilevel analysis. Social Science Medicine, 46(8), 971-979.

Schoeni, R. (1995). Marital status and earnings in developed countries. Journal of Population Economics, 8, 351-359.

Siegel, M., \& Lucke, M. (2009). What determines the choice of transfer channel for migrant remittances? The Case of Moldova. Working Papers. Kiel Institute for the World Economy.

Small, K., \& Hsiao, C. (1985). Multinomial Logit specification tests. International Econometric Review, 26(3), 619-627.

Stata Base Reference Manual Release 13. (2013). A Stata press Publication StataCorp LP (College Station, Texas)

Su, S., \& Yen, S. (2000). A censored system of cigarette and alcohol consumption. Applied Economics, 32, 729-737.

Von Fintel, D. (2007). Dealing with earnings Bracket responses in household survey - How Sharp are midpoint Imputations. South African Journal of Economics, 75(2), 293-312.

Wagenaar, A. C., Salois, M. J., \& Komro, K. A. (2009). Effects of beverage alcohol price and tax levels on drinking: A meta-analysis of 1003 estimates from112 studies. Addiction, (104), 179-210.

World Health Organisation. (2007). Who Expert Committee report on problems related to alcohol consumption. Technical Report Series 944. Geneva: World Health Organisation.

Zarkin, G., French, M., Mroz, T., \& Bray, J. (1998). Alcohol use and wages: New results from the national household survey on drug Abuse. Journal of Health Economics, 17, 53-68.

Zhang, H. (2004). Self selection and wage differentials in urban China: A polychotomous model with selectivity. Cambridge: Department of Urban Studies and Planning, Massachusetts Institute of Technology.

Zhang, Y., Hannum, E., \& Wang, M. (2008). Gender-based employment and income differences in urban China: Considering the Contributions of marriage and Parenthood. Social Forces, 86(4), 1529-1560.

Zhang, X., Zhang, Y., Aleong, T., Baker, T., \& Fuller-Thomson, E. (2012). Factors associated with the household income of persons living with HIV/AIDS in China. Global Journal of Health Science, 4(3). 